\title{
An analysis of drought evolution characteristics based on standardized precipitation index: a case study in Southwest Guizhou Autonomous Prefecture, China XU YANG", XIAOHOU SHAO, XINYU MAO, XIUNENG LI and RONGQI LI
}

\author{
College of Agricultural Engineering, Hohai University, Nanjing 210 098, China. \\ *Corresponding author: yangxucould@163.com
}

\begin{abstract}
Drought is a worldwide concerned issue which causes huge losses in agriculture, economic and damages in natural ecosystems. The precise assessment of drought evolution characteristics is essential for agricultural water management and drought resistance, while such work is rarely reported. Thus, eight meteorological stations located within the Southwest Guizhou Autonomous Prefecture (SGAP) were selected, and the Standardized Precipitation Index (SPI) was used to assess the drought evolution characteristics. The results revealed that the drought occurrences number in Pu'an station was the largest (23 droughts), and the average drought duration in Xingren station was the longest (48.75 months). Moreover, the drought characteristics of the eight stations have account for the largest proportion under normal conditions, was more than $60 \%$, the frequency of drought disaster occurring in Xingren is the highest $(30.05 \%)$, followed by Wangmo $(23.73 \%)$. The results of this study will provide theoretical guidance for drought resistance and agricultural production in Southwest Guizhou Autonomous Prefecture of China.
\end{abstract}

Keywords: Weather indices, MLR techniques, PCA, forecast

The drought, which caused by climate periodic variation, is a major natural hazard to both human societies and ecosystems (Ashraf et al., 2015; Rahman et al., 2018). Generally, droughts occur randomly and could be last for longterm in large areas (Dai, 2013; Hu et al., 2017). Compared with other natural disasters, drought possesses more negative impact on agricultural production, food safety and economic development (Bal and Minhas, 2017; Ashraf et al., 2015; Chen et al., 2015; Yang et al., 2016). Drought is considered as one of the most detrimental climatic hazards, while rare reports and efforts can be reached so far (He et al., 2011; Khadr et al., 2017). According to the previous studies, the amount of precipitation and the duration of drought period are the main factors of the drought, and drought mainly results from the deficiency of precipitation, which needs further water supplement for alleviating the water shortage in agricultural productions (Rahman et al., 2018). Meanwhile, it should also take into account the timing (i.e., the principal season of occurrence, delays in the start of the rainy season) and the effectiveness (i.e., precipitation intensity, number of precipitation events) of the rains (Pai et al., 2011). Moreover, change in global surface temperature, and precipitation pattern may increase the drought duration, its severity, and frequency of occurrence (Kostopoulou et al., 2017).
Southwest Guizhou Autonomous Prefecture (SGAP) is located in the southwest of China, which has grievously suffered from drought, main spring drought in recent decades. SGAP has an agro-based economy and most of the state falls in the seasonal drought area. SGAP is a major produce area of flue-cured tobacco in China, and the economic value of fluecured tobacco production plays an important role in agricultural production in the whole state (Yang et al., 2019). In recent years, due to the uneven distribution of rainfall resources, different degrees of water supply and demand in SGAP's major tobacco areas, especially in the transition period (spring) of flue-cured tobacco, which caused a huge impact on the growth of flue-cured tobacco and obstructed the normal growth and development of flue-cured tobacco (Yang etal., 2019).

It is evident that the drought has become a significant factor restricting the yield and quality of many crops, and the economic losses caused by droughts far exceed those by other natural disasters. So far, there is basically no systematic analysis of the regularity, frequency, extent, and duration of drought in most of China's major agricultural planting areas, and this has a great impact on water saving, drought resistance, and agricultural production. Therefore, it is urgent to analyze the evolution of drought conditions in agricultural planting 
Table 1: Meteorological stations' information in the study area.

\begin{tabular}{lccc}
\hline Station name & Latitude $\left(^{\circ}\right)$ & Longitude $\left({ }^{\circ}\right)$ & Altitude $(\mathrm{m})$ \\
\hline Pu'an & 25.47 & 104.58 & 1649.40 \\
Qinglong & 25.50 & 105.13 & 1552.70 \\
Xingren & 25.26 & 105.11 & 1378.50 \\
Zhenfeng & 25.24 & 105.38 & 1063.30 \\
Wangmo & 25.11 & 106.05 & 566.80 \\
Xingyi & 25.05 & 104.54 & 1299.60 \\
Anlong & 25.07 & 105.29 & 1394.50 \\
Ceheng & 24.59 & 105.49 & 584.80 \\
\hline
\end{tabular}

Table 2: SPI categories based on SPI values.

\begin{tabular}{ll}
\hline Category & SPI value \\
\hline Extreme wet condition & SPI $\geq 2$ \\
Severe wet condition & $1.5 \leq \mathrm{SPI}<2$ \\
Moderate wet condition & $1 \leq \mathrm{SPI}<1.5$ \\
Near normal condition & $-1<\mathrm{SPI}<1$ \\
Moderately drought condition & $-1.5<\mathrm{SPI} \leq-1.0$ \\
Severely drought condition & $-2.0<\mathrm{SPI} \leq-1.5$ \\
Extremely drought condition & $\mathrm{SPI} \leq-2.0$
\end{tabular}

areas and to provide theoretical guidance for regional agricultural production and rational agricultural water management. So far, many analysis methods have been developed for quantifying and assessing the drought event. Among all methods, Standardized Precipitation Index (SPI) is the most useful method to estimate the duration of drought and relevant intensity (Zhang et al., 2017; Paparrizos et al., 2018; Rahman et al., 2018). It is applied to determine the wet and dry events occurred on a certain period for the area where time-series precipitation data is available (Huang et al., 2015). The strength of SPI tool is used to estimate the probability of drought incidences irrespective of season, location, and climate of an area (Huang et al., 2015). Therefore, the analysis of drought extent and frequency was carried out using SPI in this study, and aims to determine the drought frequency, extent, and duration in SGAP. Finally, the above analysis could elucidate the evolution characteristics of drought change, and provide theoretical guidance for drought resistance and agricultural production in SGAP of China.

\section{MATERIALS AND METHODS}

\section{Study area}

Southwest Guizhou Autonomous Prefecture of China is located in the southwest of Guizhou Province $\left(104^{\circ} 35^{\prime} \mathrm{E}-106^{\circ} 32^{\prime} 18^{\prime} \mathrm{E} ; 24^{\circ} 38^{\prime} \mathrm{N}-26^{\circ} 11^{\prime} \mathrm{N}\right)$, and it has eight counties, which are Anlong, Ceheng, Pu'an, Qinglong, Wangmo, Xingren, Xingyi and Zhenfeng. The state belongs to the Panjiang river basin of the Pearl River, which is a typical low-latitude and high-altitude mountain area, and most of the altitude is between 1000 and $2000 \mathrm{~m}$. The SGAP is located in the sub-tropical climate zone with the annual mean temperature ranging between $13.8 \sim 19.4^{\circ} \mathrm{C}$, the average annual precipitation of $1352.8 \mathrm{~mm}$ mainly concentrated during May to September.

\section{Data sources}

Fifty five years (1961-2015) daily rainfall data for eight meteorological stations (Anlong, Ceheng, Pu'an, Qinglong, Wangmo, Xingren, Xingyi and Zhenfeng) were obtained from Meteorologic Bureau of SGAP, and the partially missing data were downloaded from National Meteorological Information Center, China Meteorological Administration (http://data.cma.cn). The detailed information from the stations is shown in Table 1.

\section{Analyzing methodology}

The Standardized Precipitation Index (SPI) (McKee et al., 1993; Chaudhari et al., 2004; Lee et al., 2018) is used to analyze the dynamics in precipitation and to explore the area with temporal precipitation deficiency. The SPI is based on the collective probability of accumulated precipitation as against the standard normal variable (Khadr, 2017), it can better reflect the intensity and duration of drought. SPI is a 
probability index, only involving precipitation (Zhang et al., 2017).

The SPI can track dry/wet events on different timescales, i.e. 1-, 3-, 6-, 9-, 12-, and 24- months. The SPI values as $1,3,6$, and 12 are calculated in this study, represented by SPI_1, SPI_3, SPI_6, and SPI_12, respectively. Many researchers have assumed the accumulated precipitation to the gamma distribution (Komuscu, 1999; Huang et al., 2015; Khadr, 2017). In this study, we set the precipitation in a certain timescale as $x$, and then the gamma probability density function is:

$g(x)=\frac{1}{\beta^{\alpha} \gamma(\alpha)} x^{\alpha-1} e^{-\frac{x_{i}}{\beta}}(x>0)$

where $\alpha>0, \beta>0$, they are shape parameters and scale parameters, respectively, $x>0$ is precipitation data, $\gamma(\alpha)$ is the gamma function and is defined as follows:

$\gamma(\alpha)=\int_{0}^{\infty} x^{\alpha-1} e^{-x} d x$

The estimated value of $\alpha, \beta$ can be obtained by the maximum likelihood estimate (MLE):

$\hat{\alpha}=\frac{1+\sqrt{1+\frac{4 k}{3}}}{4 k}$

$\hat{\beta}=\frac{\bar{x}}{\hat{\alpha}}$

where, $k=\ln (\bar{x})-\frac{\sum_{i=1}^{n} \ln \left(x_{i}\right)}{n}, n$ is the length of the precipitation sequence.

The gamma function has not been defined for $x=0$, but the precipitation may amount to zero actually, the cumulative probability converts to the following:

$$
H(x)=u+(1-u) G(x)
$$

where, $G(x)=\frac{1}{\gamma(\hat{\alpha})} \int_{0}^{x} t^{\alpha-1} e^{-t} d t, u$ is the probability that the precipitation was zero, $u=\frac{m}{n}, m$ is the number that represents the precipitation if it is zero in a temporal sequence of data.

After converting $\mathrm{H}(x)$ into a standard normal distribution function, the SPI can be obtained.

When $0<H(x) \leq 0.5$, ordered $k=\sqrt{\ln \left(\frac{1}{H(x)^{2}}\right)}$, then,

$S P I=-\left(k-\frac{c_{0}+c_{1} k+c_{2} k^{2}}{1+d_{1} k+d_{2} k^{2}+d_{3} k^{3}}\right)$
When $0.5 \quad H(x)<1$, ordered $k=\sqrt{\ln \left(\frac{1}{[1-H(x)]^{2}}\right)}$, then,

where $c_{0}, c_{1}, c_{2}, d_{1}, d_{2}$, and $d_{3}$ are constants with the following values:

$c_{0}=2.515515 \quad c_{1}=0.802853 \quad c_{2}=0.010328$

$d_{1}=1.432788 \quad d_{2}=0.189269 \quad d_{3}=0.001308$

According to the normal distribution curve of the SPI index, the drought and flood grades are divided based on the classification criteria of the National Climate Center, and the corresponding SPI index limit values are determined (Table 2).

\section{RESULTS AND DISCUSSION}

Temporal change of SPI at the time scale of twelve-months

In order to obtain the drought monitoring performance of the meteorological drought index in SGAP, the SPI values at five different time scales (i.e. 1 month, 3 months, 6 months, 9 months, and 12 months) were calculated using the meteorological data of each stations, and the arithmetic mean of SPI were used as drought indicators in the eight stations of SGAP. As shown in Fig. 1, the seasonal changes of SPI at different time scales from 1961 to 2015 in SGAP have a consistent trend of drought. SPI changes rapidly in a relatively short time scale (e.g. 1 month and 3 months), which indicates a relatively short duration of the dry or wet state. The dry and wet conditions last longer for each duration and change less frequently while with the increase of the time scale (e.g. 9 months and 12 months).

The drought assessment capability of SPI was analyzed in the eight meteorological stations (Anlong, Ceheng, Pu'an, Qinglong, Wangmo, Xingren, Xingyi, and Zhenfeng). The sequence of SPI at the 12-month annual scale was used to investigate the drought conditions in the region from 1961 to 2015. It can be seen from Fig. 2 that SPI shows an upward trend in two stations (Wangmo and Xingren), but a downward trend in the other six stations (Anlong, Ceheng, Pu'an, Qinglong, Xingyi, and Zhenfeng) during 1961-2015.

As can be seen from Fig. 2a, the station of Anlong has suffered drought in 1971-1972, 2009-2010, and 2011-2012 respectively, especially in 1971, the value of SPI_12 attained 4, indicating that the region suffered extreme drought. According to meteorological data, the average annual precipitation of Anlong (578.60 mm) in 1971, which was far below the average annual precipitation $(1184.06 \mathrm{~mm})$ from 1961 to 2015. In Fig. 2b, the station of Ceheng has suffered drought in 2004-2005, 2011-2012 and 2013-2014 

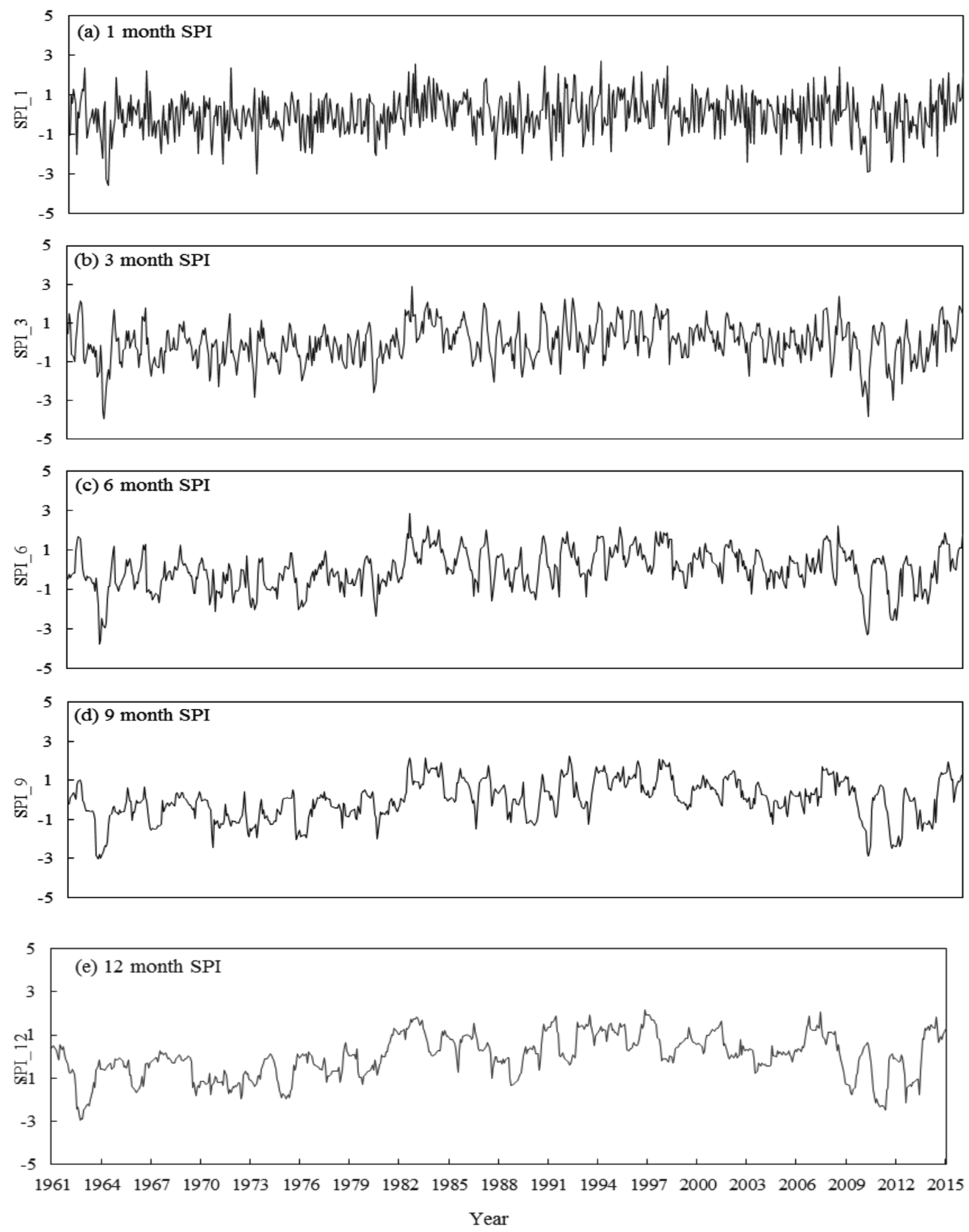

Fig 1: Sequence variation of SPI drought index at different scales from 1961-2015. 
Table 3: Frequency and duration of drought in different periods of SGAP.

\begin{tabular}{|c|c|c|c|c|c|c|c|c|}
\hline \multirow{2}{*}{$\begin{array}{c}\text { Stations } \\
\text { Drought } \\
\text { Occurrence }\end{array}$} & \multicolumn{2}{|c|}{ Anlong } & \multicolumn{2}{|c|}{ Ceheng } & \multicolumn{2}{|c|}{ Pu'an } & \multicolumn{2}{|c|}{ Qinglong } \\
\hline & $\begin{array}{c}\text { Frequency } \\
\text { (time) }\end{array}$ & $\begin{array}{l}\text { Duration } \\
\text { (month) }\end{array}$ & $\begin{array}{c}\text { Frequency } \\
\text { ( time) }\end{array}$ & $\begin{array}{c}\text { Duration } \\
\text { (month) }\end{array}$ & $\begin{array}{c}\text { Frequency } \\
\text { ( time) }\end{array}$ & $\begin{array}{l}\text { Duration } \\
\text { (month) }\end{array}$ & $\begin{array}{c}\text { Frequency } \\
\text { ( time) }\end{array}$ & $\begin{array}{l}\text { Duration } \\
\text { (month) }\end{array}$ \\
\hline $1961-1971$ & 1 & 10 & 4 & 5.5 & 5 & 3.8 & 3 & 6.33 \\
\hline $1972-1982$ & 1 & 14 & 2 & 5.5 & 3 & 2 & 1 & 1 \\
\hline $1983-1993$ & 4 & 3.5 & 4 & 3.5 & 9 & 1.78 & 4 & 3.5 \\
\hline $1994-2004$ & 3 & 4 & 3 & 2.67 & 1 & 11 & 1 & 10 \\
\hline $2005-2015$ & 4 & 9.75 & 6 & 9.67 & 5 & 7.4 & 4 & 10 \\
\hline $1961-2015$ & 13 & 6.85 & 19 & 5.95 & 23 & 3.87 & 13 & 6.46 \\
\hline \multirow{2}{*}{$\begin{array}{c}\text { Stations } \\
\text { Drought } \\
\text { Occurrence }\end{array}$} & \multicolumn{2}{|c|}{ Wangmo } & \multicolumn{2}{|c|}{ Xingren } & \multicolumn{2}{|c|}{ Xingyi } & \multicolumn{2}{|c|}{ Zhenfeng } \\
\hline & $\begin{array}{c}\text { Frequency } \\
\text { ( time) }\end{array}$ & $\begin{array}{l}\text { Duration } \\
\text { (mo nth) }\end{array}$ & $\begin{array}{c}\text { Frequency } \\
\text { ( time) }\end{array}$ & $\begin{array}{c}\text { Duration } \\
\text { (month) }\end{array}$ & $\begin{array}{c}\text { Frequency } \\
\text { ( time) }\end{array}$ & $\begin{array}{l}\text { Duration } \\
\text { (month) }\end{array}$ & $\begin{array}{c}\text { Frequency } \\
\text { ( time) }\end{array}$ & $\begin{array}{l}\text { Duration } \\
\text { (month) }\end{array}$ \\
\hline $1961-1971$ & 3 & 15 & 2 & 42.5 & 1 & 19 & 1 & 8 \\
\hline $1972-1982$ & 4 & 27.25 & 2 & 55 & 2 & 1.5 & 3 & 4.33 \\
\hline $1983-1993$ & 0 & 0 & 0 & 0 & 1 & 7 & 2 & 6 \\
\hline $1994-2004$ & 0 & 0 & 0 & 0 & 1 & 2 & 0 & 0 \\
\hline $2005-2015$ & 0 & 0 & 0 & 0 & 6 & 6.17 & 6 & 8.83 \\
\hline $1961-2015$ & 7 & 22 & 4 & 48.75 & 11 & 6.18 & 12 & 7.58 \\
\hline
\end{tabular}

respectively. Combined with the annual precipitation of 2004 , 2011, 2013, and the average annual precipitation from 1961 to 2015 , the annual precipitation in these three years is about $1000 \mathrm{~mm}$, which is less than the average annual precipitation (1251.01 mm) of 1961 to 2015. In Fig. 2c, the station of Pu'an has suffered droughts in 2011-2012 and 2013-2014. The average annual precipitation $(664.00 \mathrm{~mm}$ and $905.00 \mathrm{~mm})$ in these two years is far less than the average annual precipitation (1345.67 mm) from 1961 to 2015. In Fig. 2d, the station of Qinglong has suffered droughts in 1963-1964 and 2009-2014. During these years, it has suffered the most severe drought in 2013, and the average annual precipitation in the year was $1058.3 \mathrm{~mm}$, less than the average annual precipitation (1508.02 $\mathrm{mm}$ ) from 1961 to 2015. The drought in Wangmo (Fig. 2e) occurred before 1981, and its average annual precipitation from 1961-1981 was $162.43 \mathrm{~mm}$, much smaller than the average annual precipitation $(813.51 \mathrm{~mm})$ from 1961 to 2015 , while the average annual precipitation (1215.64 $\mathrm{mm}$ ) of 1982 to 2015, which is higher than the annual average precipitation over many years. The drought development situation in Xingren (Fig. 2f) is similar to that in Wangmo, with all the droughts occurring before 1981. The average annual precipitation of Xingren was $142.17 \mathrm{~mm}$ (1961-1981) and $1393.35 \mathrm{~mm}$ (1982-2015), and the average annual precipitation for the years 1961 to 2015 was $853.81 \mathrm{~mm}$. The station of Xingyi (Fig. 2g) has suffered drought in 1962-1963 and 2009-2012, especially an extremely arid year in 2012, with the annual precipitation was $679.9 \mathrm{~mm}$, much lower than the annual precipitation (1483.99 mm). In Fig. 2h, the station of Zhenfeng has suffered droughts in 2004-2005 and 20092014, with 2013 as the driest year. The average annual precipitation of Zhenfeng in 2013 was $813.30 \mathrm{~mm}$, which is lower than the average precipitation $(1318.09 \mathrm{~mm})$ during 1961 to 2015 . 



Fig 2: The temporal change of SPI at the time scale of twelve-months during 1961-2015. 
Table 4: Statistics of drought status in different regions reflected by SPI_12 index (\%).

\begin{tabular}{lcccccccc}
\hline Drought & Anlong & Ceheng & Pu'an & Qinglong & Wangmo & Xingren & Xingyi & Zhenfeng \\
\hline Dry & 13.71 & 17.41 & 13.71 & 12.94 & 23.73 & 30.05 & 10.48 & 14.02 \\
Normal & 73.50 & 69.34 & 68.41 & 70.26 & 75.19 & 59.94 & 77.20 & 73.04 \\
Wet & 12.79 & 13.25 & 17.87 & 16.80 & 1.08 & 10.02 & 12.33 & 12.94 \\
\hline
\end{tabular}

\section{Frequency and duration of drought using the SPI}

The frequency and duration of drought based on the SPI_12 sequence in different periods of SGAP have also been analyzed in this study. According to the drought level criteria of SPI, the SPI value less than -1, which indicates that drought occurs once. It can be seen from Table 3 that the number of droughts in Pu'an station was the largest with 23 times drought during 55 years and a drought duration average of 3.87 months. At the same time, the other seven stations have suffered droughts for 13 (Anlong), 19 (Ceheng), 13 (Qinglong), 7 (Wangmo), 4 (Xingren), 11 (Xingyi), and 12 (Zhenfeng) times, respectively. The average drought duration in Xingren station was the longest, which attained 48.75 months in this period.

It can be seen from the occurrence of drought at different periods, the statistics of SPI_12 showed that there were no droughts in Wangmo and Xingren from 1983 to 2015, while the two regions suffered 3 and 2 times drought in 1961 to 1971, respectively, and the duration were 15 and 42.5 months, respectively. Moreover, droughts have occurred 4 and 2 times in 1973-1982, respectively, and the average duration was 27.25 and 55 months. There was no droughts in Zhenfeng from 1994 to 2004, but there were 1, 3, 2 and 6 times drought in the other four periods, and the average duration were 8, 4.33, 6, and 8.33 months respectively. In addition to Pu'an, Wangmo, and Xingren stations, the remaining stations suffered the highest number of droughts in five different periods during 2005-2015. Also, in these periods, except in Wangmo, Xingren, and Xingyi stations, the average duration of drought occurring in the other five stations was longer than that of the overall period (1961-2015).

In order to further analyze the drought characteristics of SGAP, the frequency of drought was adopted using the SPI_12 sequence. Table 4 lists the drought characteristics of the eight stations from 1961 to 2015 using the categories: drought, normal, and wet conditions. The results showed that all stations in normal conditions have account for the largest proportion, and is more than $60 \%$ at the normal frequencies. Among them, the frequency in Anlong, Xingyi, and Zhenfeng are not much difference under the drought and wet conditions; however, there is a big difference between the frequency of drought $(23.73 \%)$ and that of wet conditions $(1.08 \%)$ in Wangmo. Among the eight stations, the drought disaster frequency occurring in Xingren is the highest, attained $30.05 \%$, followed by Wangmo with $23.73 \%$.

The SPI results revealed that the trend of drought in the SGAP reflected by the five scales of drought index was consistent. During the time under study, the drought episodes by meteorological stations were 23 (Pu'an), 13 (Anlong ), 19 (Ceheng), 13 (Qinglong), 7 (Wangmo), 4 (Xingren), 11 (Xingyi) and 12 (Zhenfeng) with a drought frequency of $13.71 \%, 13.71 \%, 17.41 \%, 12.94 \%, 23.73 \%, 30.05 \%, 10.48 \%$ and $14.02 \%$. The result is consistent with Shi et al. (2014), who indicated that there exists a substantial probability of extreme drought appearance, and extreme events seem to be frequently occurring from the 1960s to 2010s. Moreover, in our study, it was found that these drought events in SGAP have severely affected the irrigation management and flue-cured tobacco yields. This also confirms and supplements the research findings of Wang et al. (2015) and Chen et al. (2017), which showed that it has suffered several extreme droughts, such as the event in the summer of 2006, one from the autumn of 2009 to the spring of 2010, and one in the summer of 2011, which have resulted in tremendous economic loss, ecosystem damage, and disruption of society (Qiu, 2010; Zhang et al., 2015). In addition, crop yield is threatened by increasingly frequent winter and spring drought events (He et al., 2017). Hence, it is necessary and meaningful to analyze the evolution of drought in agricultural planting areas.

\section{CONCLUSION}

The SPI results expressed by five scale of drought index revealed that drought trend in the SGAP was consistent. The smaller-scale meteorological drought index indicates that the duration of the drought or wet state is shorter, and with the increasing of the scale, the drought and wet state lasts longer, the frequency of change becomes lower. The drought occurrences number in Pu'an station was the largest (23 droughts), and the average drought duration in Xingren was 
the longest (48.75 months). Moreover, the drought characteristics of the eight meteorological stations have accounted for the largest proportion under the normal conditions, was more than $60 \%$. However, there is a big difference between the frequency of drought $(23.73 \%)$ and that of wet conditions (1.08\%) in Wangmo station. Among the eight stations, the frequency of drought disaster in Xingren is the highest (30.05\%), followed by Wangmo (23.73\%). Finally, the above analysis have elucidated the regularity, frequency, extent, and duration of drought, which will provide theoretical guidance for drought resistance and agricultural production in Southwest Guizhou Autonomous Prefecture of China.

\section{ACKNOWLEDGEMENT}

This work was financially supported by Postgraduate Research \& Practice Innovation Program of Jiangsu Province (SJKY19_0520), the Fundamental Research Funds for the Central Universities (2019B68214, 2017B755X14), the Science and Technology project by Guizhou tobacco of China National Tobacco Corporation (201709), Science and Technology Project of Tobacco Company of Southwest of Guizhou Province (JS-JL-11/D 201502).

\section{REFERENCES}

Ashraf, M. and Routray, J.K. (2015). Spatio-temporal characteristics of precipitation and drought in Balochistan Province, Pakistan. Nat. Hazards, 77(1): 229-254.

Bal, S.K. and Minhas, P.S. (2017) Atmospheric Stressors: Challenges and Coping Strategies. In: P.S. Minhas et al. (eds) Abiotic Stress Management for Resilient Agriculture. Springer Nature Singapore Pte. Ltd., pp. 9-50.

Chaudhari, K.N. and Dahwal, V.K. (2004). Assessment of impact of draught on production of major kharif and rabi crops using standardized precipitation index. $J$. Agrometeorol., 6: 10-15.

Chen, H.P. and Sun, J.Q. (2015). Changes in drought characteristics over China using the Standardized Precipitation Evapotranspiration Index. J. Clim., 28(13): 5430-5447.

Chen, H.P. and Sun, J.Q. (2017). Anthropogenic warming has caused hot droughts more frequently in China. $J$. Hydrol., 544:306-318.

Dai, A. (2013). Increasing drought under global warming in observations and models. Nature Clim. Change, 3(1): 52-58.

He, B., Lu, A.F., Wu, J.J., Zhao, L. and Liu, M. (2011). Drought hazard assessment and spatial characteristics analysis in China. J. Geog.. Sci., 21(2): 235-249.

He, D., Wang, J., Pan, Z.H., Dai, T., Wang, E.L. and Zhang, J.P. (2017). Changes in wheat potential productivity and drought severity in southwest china. Theor. Appl. Climatol., 130(1-2): 477-486.

Hu, Y., Du, L.T., Hou, J., Liu, K. and Zhu, Y.G. (2017). Drought characteristics in arid zone of middle Ningxia from 1960 to 2012 base on SPI index. Agric. Res. Arid Areas, 35(2): 255-262.

Huang, J., Xue, Y., Sun, S.L. and Zhang, J.C. (2015). Spatial and temporal variability of drought during 1960-2012 in Inner Mongolia, north China. Q. Int., 355: 134-144.

Khadr, M. (2017). Temporal and spatial analysis of meteorological drought characteristics in the upper Blue Nile river region. Hydrol. Res., 48(1): 265-276.

Komuscu, A.U. (1999). Using the SPI to analyze spatial and temporal patterns of drought in Turkey. Drought Network News, 11(1): 7-13.

Kostopoulou, E., Giannakopoulos, C., Krapsiti, D. and Karali, A. (2017). Temporal and spatial trends of the standardized precipitation index (SPI) in Greece using observations and output from regional climate models. Pers. Atmos. Sci., 475-481.

Lee, S.K. and Dang, T. (2018). Evaluating drought events under influence of El-Nino phenomenon: A case study of Mekong delta area, Vietnam. J. Agrometeorol., 20(4): 275-279.

McKee, T.B., Doesken, N.J. and Kleist, J. (1993). The relationship of drought frequency and duration to time scales. Paper presented at the Proceedings of the 8th Conference on Applied Climatology, Anaheim, pp. 179-184.

Pai, D.S., Sridhar, L., Guhathakurta, P. and Hatwar, H. R. (2011). District-wide drought climatology of the southwest monsoon season over India based on standardized precipitation index (SPI). Nat. Hazards, 59(3): 1797-1813.

Paparrizos, S., Maris, F., Weiler, M. and Matzarakis, A. (2018). Analysis and mapping of present and future drought 
conditions over Greek areas with different climate conditions. Theor. Appl. Climatol., 131:259-270.

Qiu, J. (2010). China drought highlights future climate threats. Nature, 465: 142-143.

Rahman, G., Atta-ur-Rahman, Samiullah, Dawood, M. (2018). Spatial and temporal variation of rainfall and drought in Khyber Pakhtunkhwa Province of Pakistan during 1971-2015. Arab.J. Geosci., 11(3): 46-58.

Shi, P.F., Yang, T., Zhang, H.X. and Yang, J. (2014). Chang Law of drought and flood situation in Qianxinan area. Water Res. Power, (11): 1-4.

Wang, L., Chen, W., Zhou, W. and Huang, G. (2015). Understanding and detecting super-extreme droughts in Southwest China through an integrated approach and index. Q. J. Royal Meteorol. Soc., 142: 529-535.
Yang, M.J., Yan, D.H., Yu, Y.D. and Yang, Z.Y. (2016). SPEIbased spatiotemporal analysis of drought in Haihe River Basin from 1961 to 2010. Adv. Meteorol., 2016(1): 1-10.

Yang, X., Shao, X.H., Mao, X.Y., Li, M.H., Li, X.N. and Li, R.Q. (2019). Variability and trend analysis of precipitation during 1961-2015 in Southwest Guizhou Autonomous Prefecture (SGAP), China. J. Agrometeorol., 21(1):31-35.

Zhang, L.X. and Zhou, T.J. (2015). Drought over East Asia: A Review. J. Clim., 28(8): 3375-3399.

Zhang, Y.H., Li, W.W., Chen, Q.H., Pu, X. and Xiang, L. (2017). Multi-models for SPI drought forecasting in the north of Haihe River Basin, China. Stoch. Environ. Res. Risk Assess., 31(10), 2471-2481. 